\title{
HEURISTIC ANALYSIS IN ARCHITECTURE OF AQA-BOZORG MOSQUE- SCHOOL IN QAJAR DYNASTY
}

| Received July 11 th 2016 | Accepted September 29th 2016 | Available online December 20th 2016 |

| DOI http://dx.doi.org/10.18860/jia.v4i2.3539 |

Azarafrooz Hosseini

Department of History of Iranian Architecture, of Isfahan Art University

Isfahan, Isfahan, Iran

Azarafrouz.h@gmail.com

\section{Sareh Jormand}

Department of History of Iranian Architecture, of Isfahan Art University Isfahan, Isfahan, Iran

Sarehjormand@yahoo.com

\begin{abstract}
Architecture during Qajar dynasty has witnessed significant developments. The change which was particularly prevalent in advanced form, was the combination of two function: mosque and school. An important issue in the mosque-school typology is the spatial layout of the space, so that the two functions could maintain their independence and do not cause flaws to each other. The aim of this study is to understand how the combination of religious and educational functions in one building is. In this research Aqa-Bozorg mosque-school is analyzed by heuristic analysis method in order to recognize the different factors such as space and quality of human cognition. The result shows that this place with religious function, is not limited to religious ceremonies, vast assemblies with social or political motivation, rather it could be known as set of usual belief or hidden ones which are existed in profound layer of thinking and culture of society. So not only formal speech or sermon, rather customs, architectural features, art sights and even arrangement of main features in a religious building could convey implication to the audience who are consciously or unconsciously affected and make their ideology based on this.
\end{abstract}

KEYWORDS:

Heuristic Analyses; Mosque-School; Descriptive-Explanatory; Aqa-Bozorg; Qajar Dynasty

\section{INTRODUCTION}

Unlike painting, music or literature, architecture is an earthly concept and is considered as a container for human activities [1]. Architecture involves human beings and emotions and their living environment. Human relations with architecture is not a solid one or such as its relation with other arts. Artificial spaces that make up architecture and city, in every moment require an active communication and interaction between human beings and itself [2]. Architecture is heavily involved with human emotions. Having different arrangements, architecture forms an important area of life. Of all arts, only architecture can display the ideas and ideals of power, development and progress in symbolic forms of space as a governmental, religious or educational structure [3]. So, Aqa-Bozorg schoolmosque, as an example of a building with social implications in the field of design, form and space, can be analyzed spatially using a critical approach analysis. This structure is being analyzed trying to understand it regarding the perceptions of space and its relationship with the people who visit it and how it communicates with them. Various researchers and architects have taken steps to study the effect of architecture and different views are discussed regarding the understanding of architecture in general, but a few of them directly and immediately provided insight to issues of architecture and architectural works.
Descriptive analysis is based on the principle that the direct reference to architectural effect and reflecting on it makes it possible to understand the effect and the ideas in the mind of the architect. Descriptive analysis is naturally based on various forms of interpretation of the architecture work [4]. In this approach, the internal issues of the art work are the target of architecture criticism but external aspects like cultural, social, political, and economic issues are even unnoticed. The present study investigates the static aspects (shape and body of the building) and the dynamic aspects (sense of space and the physical experience of the environment) of the Aqa-Bozorg school-mosque architecture using descriptiveexplanatory approach.

The process that has been adopted in order to respond to study questions can be found in two sections to identify the place (building) and human being (how the architectural work communicates with its observers). So for identifying the place by going there and doing field studies, the outline of the design and the issues associated with how the designer dealt with are examined. The way the mosque and school are spatially located and architectural design ideas for achieving this harmony is another aspect being discussed as the focus of the study. By dividing the work into three different heights and three longitudinal sections, the available spaces were identified. Regarding human identification, the quality of the spaces and their interaction with the observer (sense of 
presence) has been investigated. Furthermore, the study focuses on the heart of this architecture work the sense of space is defined. Accordingly, four points can be introduced in this study in one classification, referred to as the recessed spaces. The three movement paths are the interface between the recess points, a place for changing the observers' mood and preparing them for attending the new spaces.

\section{DESCRIPTION OF AQA-BOZORG SCHOOL- MOSQUE}

Aqa-Bozorg school-mosque is attributed to Mullah Mahdi Naraqi known as Aqa-Bozorg, is located near the historical and ancient city of Kashan and close to Khawja Tajaldyn tomb. It was finished in $19^{\text {th }}$ century, coinciding with the reign of Mohammad Shah) in 1848 $\mathrm{AD}[5]$.

\section{THE INTRODUCTION OF THE BUILDING}

Aqa-Bozorg school-mosque has an entrance porch, central courtyard, and arcades. The entrance gate and entrance porch are built on the north side. After the entrance, there is a relatively large porch with ceiling fresco and other embellishments in the body. Both sides of this porch have two aisles leading to the central porch and other parts. There is an open area opposite the entrance porch which is the roof terrace of northern bed-chamber. The entrance porch also opens onto a storage room, and the servant and guardians room. Two flights of stairs connect it to the old underground hall, ablution area and the yard. The central courtyard of the building has two floors consisting of two upper and lower courtyards (garden). The Upper floor (the roof of lecture rooms and other rooms) is surrounded with pier walls and arcades from East to West, and stretches from the north to the moonlit porch and to the mosque from south. The garden leads to 12 rooms, a lecture and a storage room from East, West and South in the corner of the southwest and east and to the bedchamber and the underneath hypogeum from north. The central courtyard with a rectangle shape pond in the middle is located almost to the north-south direction. Stairs located at the corner of the yard, connect this part to the roof of the upper chamber of the courtyard that is the dome house and a series of other steps in the middle connects this roof to the hypogeum. This hypogeum is connected to the northern bed-chamber wind towers. The Dome house has an octagonal space plan and is covered with two separate dome shells with a span of 10.20 meters. The Internal height of this space is about 21 meters. Corner rooms on the front porch pillar help stabilize the main pier and create a useful space for teachers and students [6]. The porch with a main entrance connects in the middle to the small rooms and had two other ways from left and right to get connected to the porch. The spaces around the dome porch are interconnected. The complex has two Chehel-Sotun bedchambers, one on the western side of the dome house that was built shortly after the main building and the connecting corridor, the roof stairs and a place for ablution house on the north side, and another winter bed-chamber to the north of the yard and the main mosque courtyard. This bed-chamber has a stone altar in the middle of the wall, and is connected to the mosque entrance by a series of porch stairs that is the main connection for it with the outside of the mosque and is connected to the central courtyard and the garden by means of two other entrances. In the northwest of this bedchamber, there is a backyard, a pool and a place for ablution house that is connected to the main entrance porch and the mosque [7]. An overview of Aqa-Bozorg school-mosque formation of spaces and architectural analysis is presented as followed.

\section{THE SPATIAL COMPOSITION}

Regardless of any theoretical and complex definitions, architecture is an intertwined mass of building elements that reflect its existence in a particular language to the viewer. So it has its own rules of expression. Two general rules can be outlined in the expression of architecture. First, the architectural components (walls, floors, ceilings, etc.) in relation to each other are a function of internal rules. In architecture these rules or principles are related to architecture itself that somewhat follow the geometric order and the conventional construction principles. Secondly, architecture as any other constructed works has meanings apart from its internal structure which arguably results from the nature of the architectural components and the way they are combined [8]. The school-mosque stretches with an almost north-south extension and is slightly inclined to the southeast. Therefore the north-south axis regulates the order of the components of the plan is consistent with stretching bed.

Also, a transverse axis can be imagined that is less transparent than the main axis (figure 1). The main components of the structure are located on the north and south fronts and east and the walls of the eastern and western courtyard are thick, so that the depth of them has become a porch that can accommodate two or three people. The arch-chamber views help the eastern and western walls project less than expected.

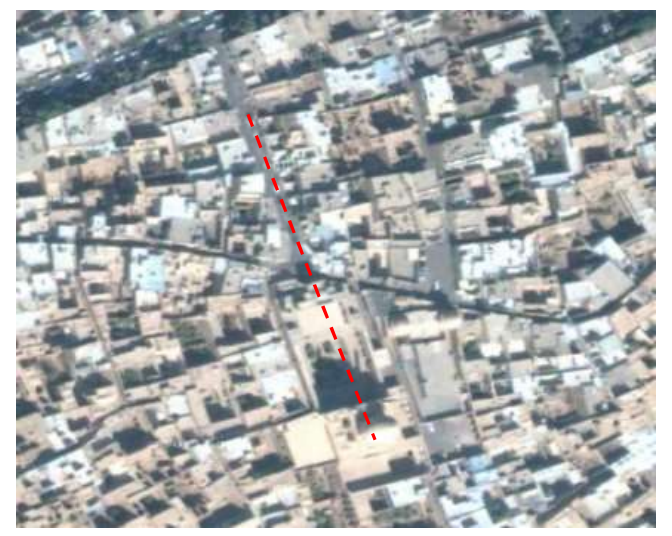

Figure 1. The North-South axis of Aqa-Bozorg mosque-school and the surrounding access (google earth)

Aqa-Bozorg school-mosque has a combination of three different heights and three longitudinal sections. 
Regarding height combinations, it must be said that the structure has a combination of a lot of different height differences and mass differences as to the height of the space and the floors, but it can be outlined in the following three general categories: The negative balance including the garden, courtyard rooms and bedchambers, Figure. 2. The zero level of the vestibule entrance, corridors leading to the courtyard, domes and surrounding open spaces and the bed-chambers, Figure. 3. And finally the corner rooms beside the dome house and rooms above the vestibule entrance are at the first

level,

Figure.

4.

For the horizontal section, it can also be said that Aqa-Bozorg school- mosque has three parts: The first part, includes the vestibule entrance, the hallway leading to the courtyard and terrace (Northern part), the second part includes the central courtyard, and the third section includes the dome house. The Open space in the middle is the focus of the Northern and Southern parts. All parts of the building open onto to the courtyard view, and thus the center of the courtyard building and the orientation of spaces is the yard, Figure. 5. After familiarization with spaces in the building and placement of each part, some issues are discussed regarding static aspects, a closer look is taken at spatial features and the questions related to it are answered. For this purpose, a short description of what the visitor seems to feel upon visiting the mosque is offered. The quality of the environment in which the structure is constructed is analyzed to get the most important spatial features (according to the observers)

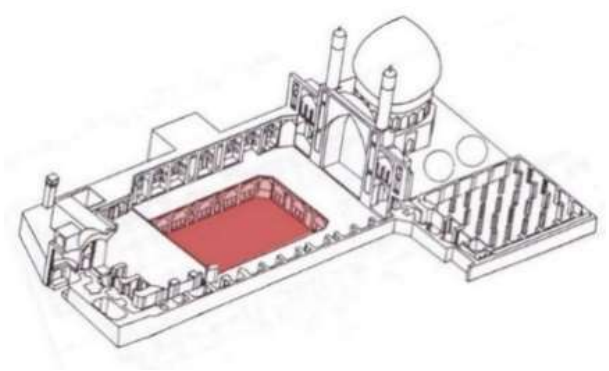

Figure 2. The negative balance spaces. (Source: Authors, 2014)

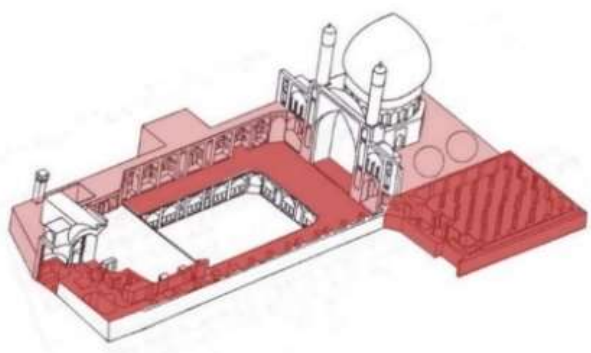

Figure 3. The zero level spaces. (Source: Authors, 2014)

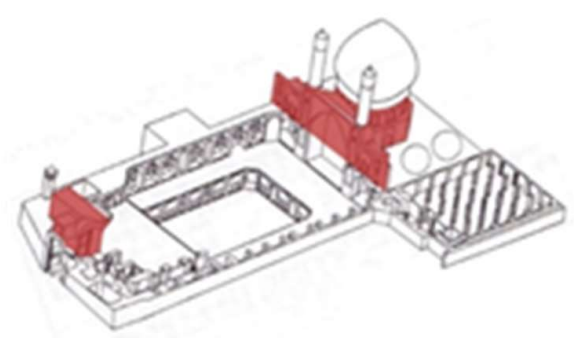

Figure 4. The first level spaces. (Source: Authors, 2014)

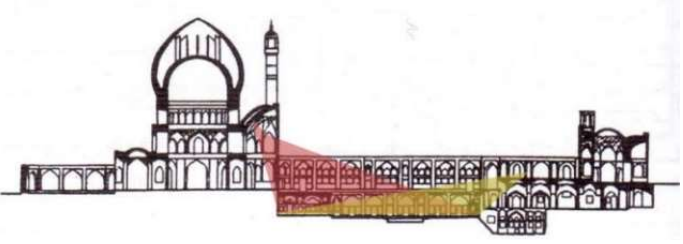

Figure 5. The focus of the northern and southern sectors of the mosque-school. (Source: Authors, 2014)

\section{THE DESCRIPTIVE-EXPLANATORY ANALYSIS OF STATIC ASPECT}

The first step is the emphasis seems to be more on the school function of the structure since in most mosque examples the overall outline of yard spaces or domes face Mecca. For example, in Sheikh Lotfollah Mosque or Isfahan Shah Mosque everything is meant to direct the prayers spaces and a person entering the mosque towards Mecca (figures 6, 7).

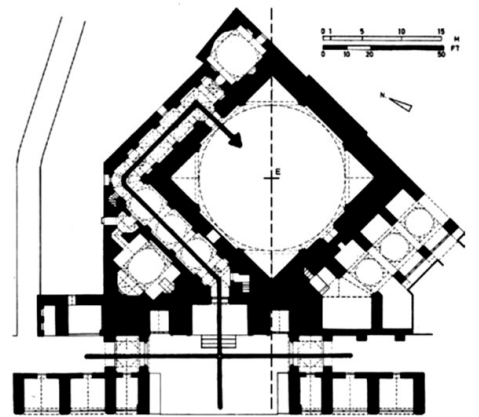

Figure 6. Displacement of the prayer hall's center from the symmetrical axis of the mosque's entrance, Sheikh Lotfollah Mosque [9].

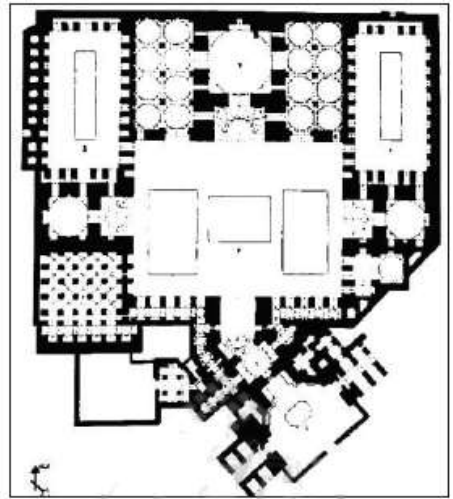

Figure 7. Displacement of the dome house axe from the mosque's main entrance, Isfahan Shah Mosque [10] 
This advantage cannot be seen in this SchoolMosque. Aqa-Bozorg school- mosque doesn't have a precise orientation towards Mecca; the bed-chambers, the dome house and sanctuary in the western and northern parts have an angle of 45 degrees to Mecca and any visitor would have problem understanding the direction of $\mathrm{Mecca}$ upon entering the mosque (figures $8,9)$.

However, the entrance to the building or even before that, the entrance of the alley leading to the mosque, what appears to be seen at first glance is the mosque's dome (figure 10). The emphasis on this part of the building, can be examined from two perspectives: First, the use of the lower level and the entry level rooms around the garden has caused the dome to look unique and be seen first and because the dome represents a mosque, at first glance it seems that this building is only meant to be a mosque. Second of all, the location of the yard in the plan, the bedchambers at a lower level and another yard on the east side of the dome helps the dome project even further and led to a greater emphasis on the dome. Such organization in the yard of the building directs an observer's attention to the dome upon entering the school-mosque.

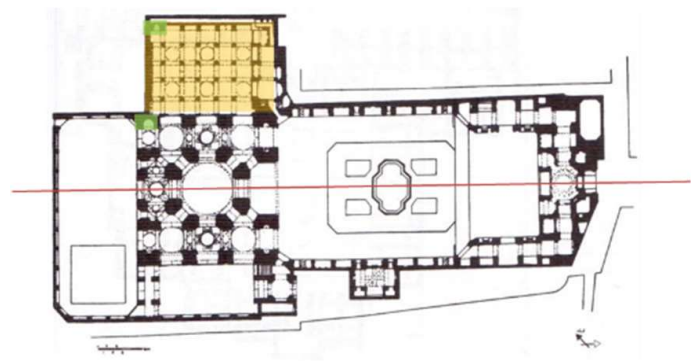

Figure 8. The ground floor plane of mosque-school, the location of bed-chamber and Mehraab and their relationship with Mecca axis and building axis. (Source: Authors, 2014)

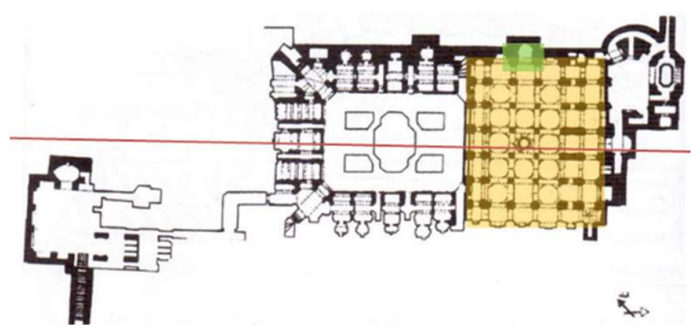

Figure 9. The basement plane of mosque-school, the location of bed-chamber and Mehraab and their relationship with Mecca axis and building axis. (Source: Authors, 2014)

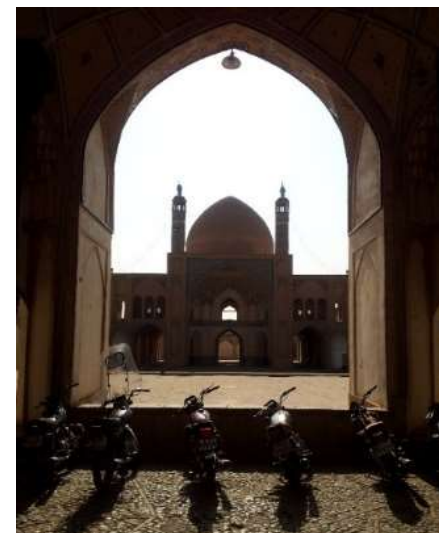

Figure 10. The view of the dome. (Source: Authors, 2013)

What is certainly important is that the observer's look was meant to be purposeful because one cannot see the whole space or know what is happening in this place upon entering it. An observer can only see the dome house through occasional openings at various intervals in the façade and part of the fluidity of the space is introduced upon entering the vestibule. At the entrance, the selected view is framed by the moonlit view and the vestibule. Having passed the corridors leading to the courtyard, an observer gets to see other areas than the dome and once one gets to the dome house they becomes aware of the yard behind the dome and open spaces connected to the dome and the bed-chambers. If one looks to the north, all space will open to him. The only thing that the observer constantly sees upon entering the structure is the dome and one will follow the longitudinal axis and in the end upon stepping inside the dome house he will feel the sense of space. The dome house as the turning point of the building is built on eight massive basis. Building domes on free foundations are rarely seen in Old dome structures in Iran. The practical result of the implementation of this type of project, in addition to creating the transparency of the atmosphere, it lets the air flow and cool air flows in the building in the desert areas. Thus, in this building, unlike the last architectural history in which the southern dome house is blocked in order to make "Mehraab" and build relatively thick walls, nothing is built in the south, southeast and southwest parts and "Mehraab" (A place for saying prayers) was built in stoic walls that encircles the dome itself.

\section{THE DESCRIPTIVE-EXPLANATORY ANALYSIS OF DYNAMIC ASPECTS}

According to the explanation given in the previous section, we can say, one can experience different feelings in any of the parts in this building. Of course, each person's expression of feelings may be different. You cannot enter this mosque and do not speak about the atmosphere, what it is going on in there and the impact it has on the observers' feelings. What happened at this location, was not only a feeling, it was a collection of different feelings that were sometimes contradictory and sometimes similar to each other. The remarkable thing is that it is designed in a way that different emotions are provoked in the observer in 
different locations of the building that could be called as the beating heart of the building. In this section we try to focus on these areas, consider them and define senses of space; and accordingly four critical points can be introduced which are organized by three movement paths, changing the observers' mood and preparing them to attend the new spaces. The First place in this building that wonders the observer is the entrance vestibule. It is in this part of the building that the observer gets to know more about the domes and minarets he had seen only part of them before entering the mosque. At this point, one would sense a feeling of clarity of the dome. The dome house and minarets that indicate heights beyond human understanding. At that moment, the perception that is formed in the observers' mind is suggestive of a powerful, solid and fixed space (figure 11). Then we enter the connecting path in which whatever happens, affects all the observers' senses. The Combination of form and space in the ceiling and walls creates the light and shade dances and the stairs on the floor which are not very steep at the same time accentuates the harmony of combinations together with the rhythms in the ceiling (figure 12). This path directs and prepares of the observer's awareness about the dome house in the vestibule and the other spaces in the building.

The observer takes the corridors and gets to the central courtyard, the next pause occurs upon his arrival at the yard. This is the point that one gets to see the garden and outdoor rooms and open space behind the dome. It is in this courtyard that the observer perceives the spatial diversity, the presence of open, enclosed and covered spaces. He has experienced diversity on the way and now realizes that they were for him to experience diversity in a larger scale. At this time the observer thinks to himself and silence, heaviness (not rigidity) and tranquility surrounds him and finding ones true self happens at this time. The observer passes through the yard and has everything in his mind and seeks to reach himself to the dome house as soon as possible and experience the feeling. By moving down the central courtyard of Aqa-Bozorg school- mosque, one's look is downward the whole time because they first became acquainted with a garden and living in it as school attracts their attention. By following the path one will get to the south porch and will be overwhelmed by the whole body of the south front which had previously seen and perceived upon entering the building from the north front and now looks up and feels the dominance of the porch and finials. It is at this point that while the observer is in the space he feels like spinning around himself and the dome house, in other word, a spinning pause. Although standing, his look spins around since from the beginning, all the way, everything was meant to direct him to this specific space. Rotating in every direction and no curtailment are the characteristics of this space (figure 13). The skylights in the Dome have created holes that look like eyes around and help create a sense of lightness and affect transparency (figure 14). The dome house is octagonal and is located under the dome. In the columned dome, no space is hidden behind a wall. Except for the pillars supporting the dome, there is not any visual barrier along the human vision. The eastern and southern yards make it possible to see an open space if an observer looks through the walls. Of course their presence does not really make sense since the building is meant to be used as a school and Mosque.

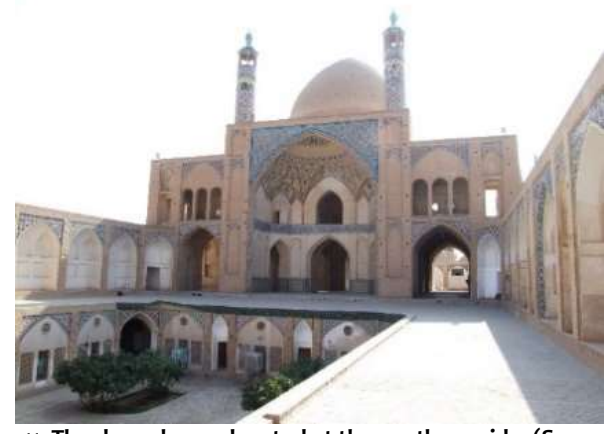

Figure 11. The dome house located at the southern side. (Source: Authors, 2013)

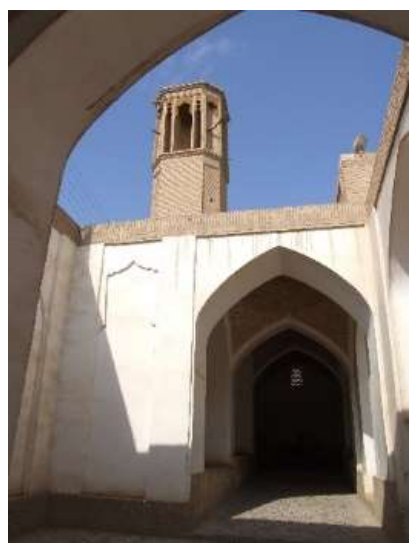

Figure 12. Communication path from the input to the central courtyard. (Source: Authors, 2013)

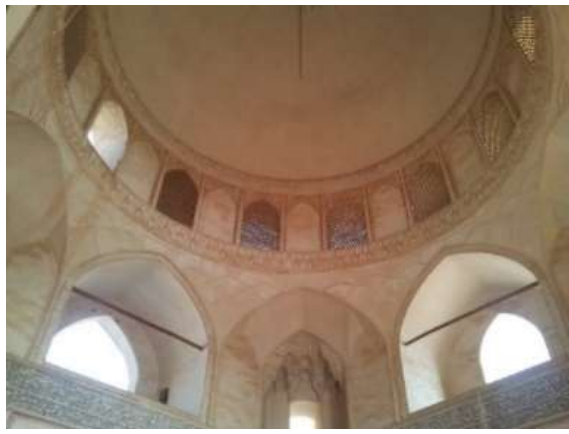

Figure 13. The expanded vision of southern side and views from all parts to the dome house. (Source: Authors, 2013) 


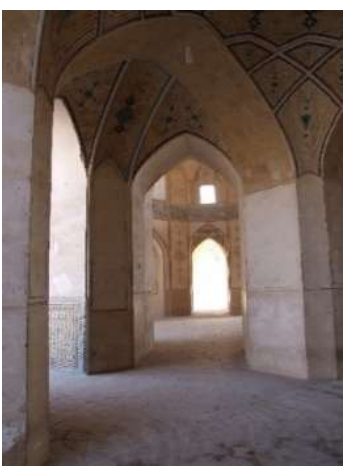

Figure 14. The open spaces around The dome. (Source: Authors, 2013)

Also the open spaces around the dome, makes it possible for the observer to rotate around the dome (although this is not a continuous rotation) and see it from different angles. This expanded vision is everywhere in the mosque, either upon entering the building from the north side one can see the end of path which is the dome house or when crossing the yard, the garden (in school) is perceivable for him. The absence of any barriers for human vision into the adjacent spaces helps the observer have an imagination of every space even before stepping into it. It is like a visitor has a memory in mind about the place before seeing each place. When the observer is inside the courtyard, although the dome and the dome height can be seen, but part of it is hidden behind the columns. This means that the space reveals and hides itself. This encourages human beings to discover what is hidden and invisible. Therefore the observer is encouraged to discover the dome house, the garden and the rooms help one from the beginning to complete his understanding of the environment.

After attending the dome house, the observer tries to access the garden and the rooms. Passing through the four corners of the yard and through the stairs gets him to this goal. Spatial diversity can be seen in access modes again since it takes the observer from an outdoor courtyard into an enclosed space (stairs), and then again prepares him to enter the indoor space. Paying attention to spatial hierarchy reduces the monotony of small spaces and increases the observer's motivation for exploring the spaces (figures 15, 16).

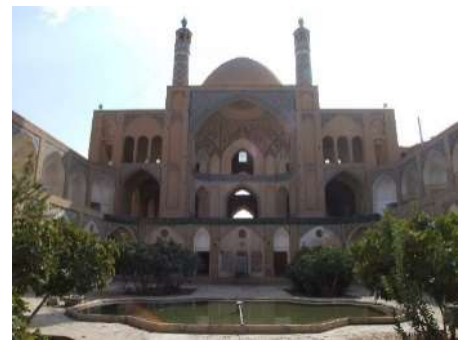

Figure 15. The view of southern side from central garden. (Source: Authors, 2013)

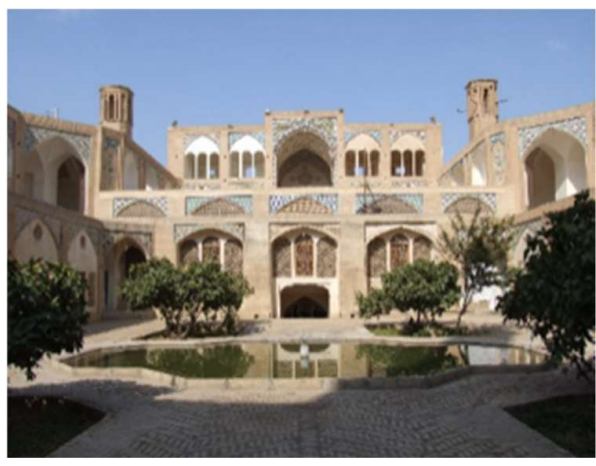

Figure 16. The view of northern side from central garden.

(Source: Authors, 2013)

\section{CONCLUSION}

The current study provides a descriptiveexplanatory analysis of Aqa-Bozorg school- mosque regardless of the deep philosophical issues in the field of art, considering it as a product of human design in order to understand the architecture's work for making the creative spaces. This is certainly based on the designer's perception of human behavior in the face of the structure. This architecture allows the viewer to have a certain experience of the space, an experience resulting from his previous experiences and the context for the next ones. Therefore, studying and analyzing the above features for understanding the place and the presence of human in the school- mosque space can be a model for modern efficient designing today.

The spatial organization of the school- mosque has created linear hierarchy which begins with the northern front and ends in the southern part as its main destination. In this spatial organization, the central courtyard after the dome house, has a high spatial value since it is an organizing element for other areas, because both the Northern and Southern parts of the building face it. Thus, the spatial layout of the building is in such a way that the masses are connected to open spaces from several directions. This combination has helped the structure with more transparency and fluidity in various parts of it. In the analysis of the functional spaces of the building it should be said that the one thing that makes the two functions possible as a single location, is paying attention to the priorities. Architectural design background of mosques in Iran shows that the attention to praying direction (Mecca) has been one of the most important principles in designing the buildings which is not taken care of in this building at all. The North-South stretching of the land has made the correct placement of the spaces of the school and the mosque and the organization of them according to the direction of Mecca has helped to observe the priorities. However, this has somehow faded the Mosque function but on the other hand the creativity of the architect by using the elements and features of the mosque, such as domes and minarets and dome spaces has helped emphasize the mosque function as well. This is one of the ways of combining two functions with identical values. In Aqa-Bozorg school- mosque building, the spaces are organized within an invisible network. Three levels of heights and three longitudinal sections have created a stabilized 
and creative space for building combinations. Using three separate levels for separate functions has also contributed to the unity of the masterpiece. The fact that certain spaces related to specific functions are defined at specific levels (the school and its related space at -1 level and the mosque at o level) has been effective in functional independence. On the other hand, placing common areas such as the yard at -1 level and the bed-chambers at o level has kept the balance and the connection so that the mosque and the school are not completely separated. The spatial organization, in addition to the dynamism and mass varieties, has made the building very scenic and eye-catching.

The spatial organization of structure, not only makes the structure dynamic but it also expands the view and adds to the beauty of it. The spatial extension of the southern front (the dome house) adds to the holiness of it and extends it to the whole southern part. The checked pattern brick wall in the northern front that separates the southern bed-chambers from the garden also prevents the bed-chambers from getting dark during the day.

Therefore all the spaces within this invisible net are simultaneously independent and combinatory. Smaller spaces are precisely defined and can be combined to extend. The spatial diversity (open, enclosed and covered) together with materials variety (brick, stone, wood and chalk) help the observers experience different feelings the spaces will never become repetitious. It is not one specific feeling, it's a combination of feelings which are sometimes contradictory and sometimes accentuate each other.

The remarkable thing is that the design is based on different functions, and this in fact causes different emotions arouse in the observer which can unconsciously affect the observer's overall mindset about the world.

\section{REFERENCES}

[1] M. Hojjat, "Cultural Heritage In Iran: Policies For An Islamic Country," University of York, 1995.
[2] Iranian-Architect, "Interview With Mehdi Hojjat-8: Architecture and Psychology," 2016. [Online]. Available: iranianarchitect.ir/tag/mehdi-hojjat. [Accessed: 15Feb-2016].

[3] G. H. Baker, Design Strategies in Architecture. New York: Van Nostrand Reinhold, 1992.

[4] W. Attoe, Architecture and Critical Imagination. Tehran: Farhangestan Honar pub, 2010.

[5] "Agha_Bozorg_mosque," Wikipedia, 2014. [Online]. Available: wikipedia.org/wiki/Agha_Bozorg_mosque. . [Accessed: 23-Nov-2013].

[6] K. Haji-Qassemi, "Ganjnameh: Mansions of Kashan, Cylopaedia of Iranian Islamic Architecture," Tehran, 1996.

[7] S. Khaghani, Islamic Architecture in Iran: Poststructural Theory and The Architectural History of Iranian Mosques. I. B. Tauris pub, 2012.

[8] A. Saremi and T. Radmehr, Sustainable values in Iranian architecture. Tehran: Iranian Cultural Heritage pub, 1998.

[9] H. Soltanzadeh, "Fazaha- ye voroodi dar memari- ye sonatti- ye Iran," in Entrance spaces in traditional Iranian architecture, Tehran: Tehran Municipality, Social and Cultural Affairs pub, 1993.

[10] M. Ahmadi, "Recognition of Islamic Philosophic Effects on Traditional Architecture of Iran," J. Philos. Perceptions, vol. 1, no. 2, pp. 93-137, 2009. 